\title{
Potential nephrotoxic effects of exposure to silver
}

\author{
K D ROSENMAN, ${ }^{1}$ N SEIXAS, ${ }^{1}$ I JACOBS ${ }^{2}$ \\ From the New Jersey Department of Health, ${ }^{1}$ CN 360, Trenton, New Jersey 08625, and University of \\ Medicine and Dentistry of New Jersey, ${ }^{2}$ USA
}

\begin{abstract}
A cross sectional study was conducted on workers engaged in manufacturing precious metal powder. Of the 27 workers, $96 \%$ had raised urine silver concentrations (range $0.5-52.0 \mu \mathrm{g} / \mathrm{l}$, mean $11.3 \mu \mathrm{g} / \mathrm{l}$ ) and $92 \%$ had raised blood silver concentrations (range $0.05-6.2 \mu \mathrm{g} / 100 \mathrm{ml}$, mean $1.0 \mu \mathrm{g} / 100 \mathrm{ml}$ ). Nineteen per cent also had raised urine cadmium concentrations (range 1.9-76.0 $\mu \mathrm{g} / 1$, mean $11.8 \mu \mathrm{g} / \mathrm{l})$. Most workers had symptoms of respiratory irritation and nose bleeds were reported in eight $(30 \%)$ of the 27 workers. Deposition of silver in the cornea of the eye was detected in five of eight $(63 \%)$ of the long term workers. Although not statistically significant, corneal deposition was associated with complaints of decreased night vision. The urinary enzyme N-acetyl-B-D glucosaminidase (NAG) was significantly raised in four individuals and was correlated with blood silver concentrations and age. In addition, the group's average NAG concentration was significantly higher than that found in a control population. No association between age and urinary NAG was found in the control group. Estimated creatinine clearance was also significantly lower in the group exposed to silver than in the control group. Kidney function appears to have been adversely affected by exposures at work but because of the exposure to cadmium the role of silver in causing the decrement in kidney function could not be definitely determined.
\end{abstract}

There are no known acute effects of exposure to silver metal but some silver compounds such as silver oxide and silver nitrate are irritating and exposure to them has been associated with nose bleeds and abdominal pain. ${ }^{1}$ With chronic exposure, silver binds to sulphydryl proteins in cells and, depending on the duration and amount of exposure, individuals may develop darkening of the conjunctiva and darkening of the skin especially in sun exposed areas. The darkening may be described as a slate grey colour. The chronic effects of silver are considered to be limited to these changes in the pigmentation of the skin and eyes without any corresponding functional defects.

Silver is also deposited in the cornea of the eye. In a previous study of silver exposure extensive eye examinations to follow up complaints of decreased night vision in workers with corneal opacities from silver showed no cause for this complaint. ${ }^{2}$ Whether silver affects the kidney like other heavy metals such as mercury or cadmium has not been specifically investigated. One previous study in workers exposed to silver found limited evidence of an effect of silver on creatinine clearance. ${ }^{1}$ The present study examines the chronic effects of exposure to silver, concentrating on the effects on renal function.

Accepted 21 July 1986

\section{Industrial hygiene and background}

The company in which the study was undertaken manufactures silver and other precious metal powder. It uses pure metals (silver bars, cadmium, gold, platinum, and paladium) as well as silver containing wastes (spent chemical catalysts) as its raw materials. Numerous chemicals including nitric acid, hydrochloric acid, formaldehyde, caustics, hydroquinone, and solvents are used in the refining process. Products from the plant include several grades of powdered metals and wire.

About 220 workers are employed at the plant in all phases of the operation, including about 30 maintenance workers and 150 in production.

Silver powders are produced for use in other plant processes and for sale as pure silver. The powder is manufactured by adding silver nitrate, water, and formaldehyde into a reactor vessel which is then heated. Sodium carbonate is added and the product decanted into a centrifuge on a lower level of the plant. Workers then manually scoop the silver cake from the centrifuge. The powder is dried, pulverised, screened, and packaged in several grades in 55 gallon drums.

Silver nitrate, silver oxide, silver chloride, and silver cadmium oxide powders are produced with variations in the process described above. In addition, silver 
metal ingots are produced in a foundary area in which metals are melted and poured into moulds. A federal Occupational Safety and Health Administration health inspection was conducted at the plant and time weighted exposures to silver ranged from $0.04-0.35 \mathrm{~mm} / \mathrm{m}^{3}$. Operators were wearing powered air purifying respirators during some dusty jobs.

\section{Methods}

Testing consisted of a detailed questionnaire, slit lamp examination by an ophthalmologist, measurement of weight, urinary concentrations of silver and cadmium, a blood silver concentration, blood chemistry including blood urea nitrogen, and creatinine and urinary n-acetyl-B-D glucosaminidase (NAG). Estimated creatinine clearance was calculated from the serum creatinine, reported age, and measured weight. ${ }^{3}$ Creatinine clearance was corrected to a standard body surface area of $1.73 \mathrm{~m}^{3}$

All employees who had worked for at least two years in silver flake, silver nitrate, silver powder, or the refinery area; maintenance workers who had worked for more than five years at the plant; and workers from any area who had worked for more than 10 years were asked to participate and 27 workers agreed to do so. The seven individuals who did not participate included two long term workers from non-silver areas, three workers from silver nitrate, one silver flake worker, and one maintenance worker.

Trained interviewers administered the questionnaire. The eye examinations were conducted with a portable slit lamp and the ophthalmologist was unaware of the work histories of the individuals being examined. He coded conjunctival and corneal findings on a 1-4 scale, based on a previously developed scoring system. ${ }^{1}$ Commercial laboratories performed the blood chemistry (METPATH) and urine silver ${ }^{4}$ and cadmium $^{5}$ analyses (National Medical Laboratories). Blood silver analysis was performed by the New Jersey Department of Health Laboratories, ${ }^{6}$ and NAG analysis was conducted by Cornell Medical Center. ${ }^{7}$

Analyses for cadmium, silver, and NAG were performed on spot urine samples. Urinary silver and cadmium concentrations were reported as micrograms of metal per litre of urine. For all analysis relating urine metal concentrations with health effects (correlations and regressions), however, the urinary metal levels were corrected for urine concentration by expressing them as micrograms of metal per milligram creatinine.

Both systolic blood pressure greater than $160 \mathrm{~mm} \mathrm{Hg}$ and urinary protein on dipstick of $2+$ or greater have been associated with raised NAG concentrations. ${ }^{7}$ Therefore, for the statistical analyses of NAG individuals with either of the above abnormal- ities were excluded; this left 23 individuals for these analyses.

An additional analysis of the effect of silver on NAG and creatinine clearance was conducted comparing urinary NAG in the group as a whole with results of NAG in an unexposed control populatiou consisting of the first 28 of 51 male workers from $\overline{\bar{a}}$ tungsten carbide machine shop who were being stu市 ied for the pulmonary effects of tungsten carbide and cobalt exposure. Five individuals from the control group were excluded from the analysis because $\overline{\mathscr{A}}$ raised blood pressure (systolic $>160 \mathrm{~mm} \mathrm{Hg}$ ) or urie nary protein on dipstick of $2+$ or greater.

\section{Results}

The average age of the 27 subjects was 41 and they hat worked at the plant for an average of $8 \cdot 1$ years (table 1).

Based on inspection of the plant and job title individuals were categorised as working in one of si* exposure groups. The number of individuals par ticipating from each of the six areas were: five from. silver crystal, four from silver flake, six from silvę powder, five from melting, three from refinery, and four from "all over." The all over category included maintenance and supervisory job titles involving work in many areas of the plant.

Table 2 gives the results of biological monitoring

Table 1 Prevalence of conjunctival and corneal changes $* \stackrel{\stackrel{D}{\perp}}{\stackrel{2}{2}}$ by duration of exposure

\begin{tabular}{|c|c|c|c|c|c|}
\hline \multirow[b]{2}{*}{ Years worked } & \multirow[b]{2}{*}{ No } & \multicolumn{2}{|c|}{$\begin{array}{l}\text { Conjunctival } 2+ \\
\text { or greater }\end{array}$} & \multicolumn{2}{|c|}{ Cornea $4+$} \\
\hline & & $N o$ & $\%$ & No & $\%$ \\
\hline $\begin{array}{l}<2 \\
2-5 \\
5-10 \\
>10\end{array}$ & $\begin{array}{l}2 \\
9 \\
8 \\
8\end{array}$ & $\begin{array}{l}0 \\
2 \\
3 \\
5\end{array}$ & $\begin{array}{r}0 \\
22 \\
38 \\
63\end{array}$ & $\begin{array}{l}0 \\
1 \\
0 \\
5\end{array}$ & $\begin{array}{r}0 \\
11 \\
0 \\
63\end{array}$ \\
\hline Total & 27 & 10 & 37 & 6 & 22 \\
\hline
\end{tabular}

*Grading system for evaluation of pigmentation of conjunctival 0 and corneal silver deposition ${ }^{1}$ :

\begin{tabular}{|c|c|c|}
\hline Grade & Conjunctiva & Cornea \\
\hline Trace & $\begin{array}{l}\text { Equivocal pigment change } \\
\text { in slit lamp view }\end{array}$ & Equivocal pigment cha \\
\hline $1+$ & $\begin{array}{l}\text { Detectable by slit lamp } \\
\text { but not by unaided eye }\end{array}$ & $\begin{array}{l}\text { Minimal pigment change } \\
\text { Descemet's membrane, } \\
\text { centrally or peripherally } \\
\text { just inside limbus }\end{array}$ \\
\hline $2+$ & $\begin{array}{l}\text { Detectable without slit } \\
\text { lamp on caruncle or } \\
\text { inferior fornix, or both }\end{array}$ & $\begin{array}{l}\text { Present as in } 1+, \\
\text { becoming patchy at one } \\
\text { location }\end{array}$ \\
\hline $3+$ & $\begin{array}{l}\text { Confluent involvement } \\
\text { from caruncle to inferior } \\
\text { fornix }\end{array}$ & $\begin{array}{l}\text { Nearly generalised } \\
\text { involvement of cornea at } \\
\text { level of Descemet's } \\
\text { membrane with relative } \\
\text { spared areas remaining }\end{array}$ \\
\hline $4+$ & $\begin{array}{l}\text { Pronounced involvement } \\
\text { of conjunctiva elsewhere }\end{array}$ & $\begin{array}{l}\text { Diffuse involvement } \\
\text { throughout cornea, at le的 } \\
\text { of Descemet's membrane }\end{array}$ \\
\hline
\end{tabular}


Table 2 Mean urinary silver, blood silver, and urinary cadmium concentrations

\begin{tabular}{lllll}
\hline & No & Mean & Range & Abnormal No (\%) \\
\hline Urine silver $(\mu \mathrm{g} / \mathrm{l})$ & 27 & 11.3 & $0.5-52.0$ & $26(96)$ \\
Blood silver $(\mu \mathrm{g} / 100 \mathrm{ml})$ & 26 & 1.0 & $0.05-6.2$ & $24(92)$ \\
Urine cadmium $(\mu \mathrm{g} / \mathrm{l})$ & 27 & 11.8 & $1.9-76.0$ & $5(19)$ \\
\hline
\end{tabular}

Upper limit for unexposed groups: urine silver $<1.91 \mu \mathrm{g} / 1^{8}$; blood silver $<0.27 \mu \mathrm{g} / 100 \mathrm{ml}^{6}$; urine cadmium $<10 \mu \mathrm{g} / 1 .{ }^{9}$

for metal exposure (urine silver, blood silver, and urine cadmium concentrations). Twenty six had urine silver concentrations higher than expected in an unexposed population, 24 had raised blood silvers, and five had raised urine cadmium concentrations. Blood and urinary silver concentrations were similar in individuals from different work areas. The raised cadmium concentrations were primarily in workers from the melting and powder departments.

Table 3 shows the correlation coefficients between metal concentrations and age and years worked. Urinary cadmium was significantly $(p<0.05)$ related to years worked.

To check if the metal concentrations varied with cigarette smoking, mean urine silver, urine cadmium, and blood silver concentrations were compared between current, never, and ex-smoking groups. No statistically significant differences were noted for blood or urine silver concentrations. Urine cadmium was higher in the never smoked group than in current or ex-smokers indicating that urine cadmium concentrations were not primarily caused by cigarette smoking. (The mean cadmium concentrations by smoking group were, never: 0.017, current: 0.01, ex: $0.004 \mu \mathrm{g} / \mathrm{mg}$ creatinine.)

\section{RESPIRATORY SYSTEM COMPLAINTS}

Overall, 15 of the 27 workers (56\%) complained of mucosal irritation such as itchy, red, or water eyes, sneezing, runny or stuffy nose, or sore throat. Nine complained of lower respiratory symptoms such as cough, wheezing, or tightness in the chest. Complaints of upper or lower respiratory symptoms were most prevalent in the crystal, powder, and melting departments. No significant association was found between smoking status and respiratory complaints.

Eight of the $27(30 \%)$ complained of nose bleeds, including four of the five individuals in the crystal area. Respiratory system complaints had no statistical relation with the results of biological monitoring.

Table 3 Correlation coefficients for results of biological monitoring, age, and seniority

\begin{tabular}{lcl}
\hline & Age & Seniority \\
\hline Urine silver concentrations & -0.03 & 0.22 \\
Blood silver concentrations & -0.02 & 0.02 \\
Urine cadmium concentrations & 0.19 & $0.43^{*}$ \\
\hline$* 0<0.05$ & &
\end{tabular}

\section{VISION}

Six of the $27(22 \%)$ reported difficulty seeing at night. Results of the slit lamp examination showed that 17 men $(63 \%)$ had conjunctival depositions with 10 of them rated greater than $2+$. Six subjects $(22 \%)$ had corneal depositions, all score $4+$. Individuals with corneal opacities were 3.5 times more likely to report problems with night vision than those with negative corneal slit lamp examination results but this association did not reach statistical significance.

Table 1 shows the distribution of slit lamp findings by years worked at the plant. Conjunctival discoloration increased with the length of time an individual had worked in the plant. All but one of the workers with corneal opacities had worked for more than 10 years and over half the workers with more than 10 years at the plant had corneal opacities. Urinary silver, blood silver, and urinary cadmium concentrations were not associated with the presence of slit lamp findings or with reported night vision symptoms.

\section{KIDNEY FUNCTION}

Table 4 shows the population characteristics, creatinine clearance, and urinary NAG results of the exposed and control groups. There was no significant difference in age between the study and control groups. The mean creatinine clearance of the exposed group was statistically lower than that of the control group. Urinary NAG was significantly higher in the study group than in the controls $(p<0.01)$ and the only abnormal NAGs $(>79)$ were in the study group.

Correlation coefficients between metal concen-

Table 4 Comparison of NAG and estimated creatinine clearance levels in exposed workers and controls

\begin{tabular}{|c|c|c|}
\hline & Exposed & Control \\
\hline $\begin{array}{l}\text { No for NAG analysis } \\
\text { Mean age } \\
\text { Mean NAG (SD) } \\
\text { (nmoles/h/mg Cr) } \\
\text { Range (nmoles/h/mg Cr) } \\
\text { No of workers with NAG }>79 \\
\text { nmoles } / \mathrm{h} / \mathrm{mg} \mathrm{Cr} \\
\text { No for creatinine clearance } \\
\text { analysis } \\
\text { Mean creatinine clearance (SD) } \\
\text { (ml/min } / 1.73 \mathrm{~m})^{2} \\
\text { Range }\left(\mathrm{ml} / \mathrm{min} / 1.73 \mathrm{~m}^{2}\right)\end{array}$ & $\begin{array}{l}23 \\
39 \cdot 8 \\
52 \cdot 5(46 \cdot 3) \\
12 \cdot 0-224 \cdot 0 \\
4 \\
26 \\
84 \cdot 6(14 \cdot 6) \\
59 \cdot 6-119 \cdot 7\end{array}$ & $\begin{array}{l}23 \\
38 \cdot 5 \\
13 \cdot 2(11 \cdot 8)^{* *} \\
0 \cdot 6-42 \cdot 0 \\
0 \\
27 \\
102 \cdot 8(23 \cdot 0)^{*} \\
58 \cdot 4-155 \cdot 0\end{array}$ \\
\hline
\end{tabular}


Table 5 Correlation between results of biological monitoring, age, seniority, and renal function

\begin{tabular}{lccc}
\hline & $\begin{array}{c}\text { Creatinine } \\
\text { clearance } \\
(n=27)\end{array}$ & NAG & ln NAG \\
\cline { 3 - 4 } & $(n=23)$ & $(n=23)$ \\
\hline Urine silver concentration & -0.01 & 0.29 & 0.22 \\
Blood silver concentration & 0.18 & $0.60^{*}$ & $0.43^{*}$ \\
Urine cadmium & -0.30 & 0.12 & 0.09 \\
concentration & $-0.42^{*}$ & 0.15 & 0.14 \\
Seniority & $-0.81^{*}$ & $0.65^{*}$ & $0.63^{*}$ \\
Age & - & -0.30 & -0.25 \\
Creatinine clearance & & & \\
\hline *p $<0.05$. & & &
\end{tabular}

trations and tests of renal function are given in table 5. Estimated creatinine clearance was highly correlated with years worked at the plant and age. Multiple regression results including age and urine cadmium concentrations are given in table 6. Age was significantly associated with creatinine clearance although the biological indicators of exposure and blood silver and urine cadmium concentrations were not significant predictors $(p>0.05)$.

The NAG values obtained in this study were not normally distributed and were therefore transformed for further analysis by taking their natural logarithms. A histogram of 1 n NAG (natural logarithm of NAG) approximated normal distribution appropriate for regression analysis. Correlation coefficients between biological indicators of exposure and urinary NAG are shown in table 5 .

NAG was highly correlated with blood silver concentrations and age, and there was a borderline statistically significant correlation with urine silver concentrations. When the In of NAG was taken, these correlations were reduced. Nevertheless, In NAG was still statistically associated with age $(p<0.01)$ and statistically associated with blood silver concenf trations $(p=0.048)$. A similar correlation in the cor $\vec{F}$ trol group indicated no association between age and urinary NAG $(r=-0.03, p>0 \cdot 10)$.

Results of a multiple regression on In NAG are presented in table 7. In this analysis age was a high significant variable $(p<0.001)$. Blood silver concer 2 trations contributed significantly to the variance in NAG ( $p<0.001)$; however, when controlling for age blood silver concentrations lost statistical significance $(p=0 \cdot 137)$. Neither urine cadmium concentrations nor years worked were significant variables in thes\& equations.

\section{Discussion}

The objective of this study was to determine the effece of exposure to silver. In addition to eye and respirao tory complaints, special emphasis was placed on the evaluation of possible kidney damage but because cadmium was present, its nephotoxic effect had also to. be controlled for.

Twenty seven of the workers considered to have the greatest potential for silver exposure participated in the study. This small group limits the statistical poweg of the findings and precludes definite conclusion of rates of illness in the whole population. Nevertheless the findings do indicate acute irritation problems ang eye and kidney effects associated with plan exposures.

Limited information on actual environmental levels of silver exposure or other air contaminants wasobtained. Previous air sampling, however, consise tently showed high air silver concentrations, ofte

Table 6 Regression equations on estimated creatinine clearance

\begin{tabular}{|c|c|c|c|c|}
\hline Independent variable & $D F$ & $B$ & $p$ & $r$-squared \\
\hline $\begin{array}{l}\text { Constant } \\
\text { Age }\end{array}$ & 24 & $\begin{array}{l}126 \cdot 5 \\
-1 \cdot 0\end{array}$ & $\begin{array}{c}<0.001 \\
0.009\end{array}$ & 0.684 \\
\hline $\begin{array}{l}\text { Constant } \\
\text { Urine cadmium concentration }\end{array}$ & 24 & $\begin{array}{r}87 \cdot 4 \\
-319 \cdot 8\end{array}$ & $\begin{array}{c}<0.001 \\
0.138\end{array}$ & 0.089 \\
\hline $\begin{array}{l}\text { Constant } \\
\text { Blood silver concentration }\end{array}$ & 24 & $\begin{array}{r}82 \cdot 4 \\
219 \cdot 4\end{array}$ & $\begin{array}{c}<0.001 \\
0.383\end{array}$ & 0.032 \\
\hline $\begin{array}{l}\text { Constant } \\
\text { Age } \\
\text { Urine cadmium concentration }\end{array}$ & 23 & $\begin{array}{r}126.5 \\
-1.0 \\
-158.6\end{array}$ & $\begin{array}{c}<0.001 \\
<0.001 \\
0.238\end{array}$ & 0.669 \\
\hline
\end{tabular}

Table 7 Regression equations on In urinary NAG

\begin{tabular}{|c|c|c|c|c|}
\hline Independent variable & $D F$ & $B$ & $p$ & r-squared \\
\hline $\begin{array}{l}\text { Constant } \\
\text { Age }\end{array}$ & 21 & $\begin{array}{l}2.4 \\
0.03\end{array}$ & $\begin{array}{c}<0.001 \\
0.009\end{array}$ & 0.283 \\
\hline $\begin{array}{l}\text { Constant } \\
\text { Blood silver concentration }\end{array}$ & 20 & $\begin{array}{r}3 \cdot 2 \\
59 \cdot 1\end{array}$ & $\begin{array}{c}<0.001 \\
0.048\end{array}$ & $0 \cdot 182$ \\
\hline $\begin{array}{l}\text { Constant } \\
\text { Age } \\
\text { Blood silver concentration }\end{array}$ & 19 & $\begin{array}{c}2.02 \\
0.03 \\
37 \cdot 4\end{array}$ & $\begin{array}{c}<0.001 \\
0.005 \\
0.137\end{array}$ & 0.470 \\
\hline
\end{tabular}


above the Occupational Safety and Health Administration standard of $0.01 \mathrm{mg} / \mathrm{m}^{3}$. Biological measures of silver exposure (blood and urine silver) were raised in most workers $(96 \%$ of the urine silver concentrations were greater than $1.91 \mu \mathrm{g} / 1^{8}$ and $92 \%$ of the blood silver concentrations were greater than $0.27 \mu \mathrm{g} / 100 \mathrm{ml}$. ${ }^{6}$ No correlation was found between raised blood and urine concentrations and the work area. This is not surprising since many workers used powered air purifying respirators in heavy exposure jobs. In 11 workers the urine cadmium concentration was raised above the recommended limit $(10 \mu \mathrm{g} / \mathrm{l}){ }^{9}$

As has been reported in other studies of the effect of exposure to silver, 15 workers had irritation of the eye, nose, and throat and nine had respiratory symptoms such as cough, wheezing, and chest tightness $(33 \%) .{ }^{1}$ Eight of the study group complained of nose bleeds. Few complained of abdominal discomfort. Silver compounds such as silver oxide and nitrate are irritating materials and probably account for these symptoms.

Difficulty seeing at night was reported by six workers in this group. Those individuals with corneal opacities were more likely to report problems with night vision than those with no detectable opacities, a finding that has been reported previously in silver workers. ${ }^{2}$ In this earlier study an attempt was made to explain the association using electrophysiological measurements. Although unable to identify a physiological basis for the association, these investigators were unable to exclude reduced light penetration and scatter as a cause of the symptoms.

Kidney function was evaluated by the use of both a sensitive measure of tubular dysfunction, urinary NAG, and estimated creatinine clearance. Estimated creatinine clearance was not directly associated with urine cadmium, blood silver, or urine silver concentrations (table 5). Creatinine clearance was, however, significantly depressed in the study group compared with an unexposed control population (table 4). Despite the absence of a direct association between creatinine clearance and urine cadmium concentrations, the decreased creatinine clearance in the study group is consistent with current knowledge about cadmium toxicity. ${ }^{10}$

Urinary NAG was not statistically related to changes in urinary cadmium concentrations. Urinary NAG levels were significantly higher in the exposed than in the control group (table 4) and positively correlated with blood silver concentrations (table 5). When controlling for age, however, blood silver concentration was not a statistically significant predictor (table 7). In the control group there was no association between age and urinary NAG. Although these findings suggest that silver is responsible for the raised NAG levels, some question remains since the study group was exposed not only to cadmium but also to solvents; solvent exposure has also been associated with an increased NAG level. ${ }^{7}$

NAG is a measure of damage to the proximal tubule in the kidney whereas creatinine clearance is a measure of glomerular function. Excess exposure to cadmium has been associated with both tubular and glomerular dysfunction ${ }^{11}$ but the tubular dysfunction has been identified with the use of $\beta$-2-microglobulin and not NAG. The relation between NAG and $\beta$-2-microglobulin is not clear, since among workers exposed to mercury raised levels of NAG have been found in individuals with low or normal levels of $\beta$-2-microglobulin. ${ }^{12}$

The rise of urinary NAG above normal limits is thought to be a possible indicator of progressive renal damage and has been reported to decline to normal levels when individuals are treated for hypertension. ${ }^{13}$ Our finding of four silver exposed individuals with NAG levels above the expected values and an association of NAG level with blood silver is suggestive of a toxic effect of silver on the kidney. On the basis of the present information, however, it is not possible to determine if the observed NAG rises are due to silver deposition or other renal toxins such as cadmium. Whether or not these conditions will progress to permanent damage to the kidney cannot be answered in the present study.

We thank Dr Marcus Reidenberg for performing the analysis for $\mathrm{N}$-acetyl-B-D glucosaminidase and for reviewing and suggesting improvements in the manuscript. We also appreciate Cynthia Case's patient preparation of the manuscript.

\section{References}

1 Rosenman KD, Moss A, Kon S. Argyria: clinical implication of exposure to silver nitrate and silver oxide. J Occup Med 1979;21:430-5.

2 Moss AP, Sugar A, Hargett NA, et al. The ocular manifestations and functional effects of occupational argyrosis. Arch Ophthalmol 1979;97:906-8.

3 Cockcroft DW, Gault MH. Prediction of creatinine clearance from serum creatinine. Nephron 1976;16:31-41.

4 Sachdev SL, West PW. Concentration and determination of traces of metal ions. Analytica Chimica Acta 1969;44:301-7.

5 Modification of methods reported in Atomic Absorption Newsletter 1966;5:89; Atomic Absorption Newsletter 1970;9:119; Anal Chem 1969;41:24; and Anal Chem 1962:34:614.

6 Howlett C, Taylor A. Measurement of Ag in blood by AAS using the micro-cup technique. Analyst 1978;103:916-20.

7 Meyer BR, Fischbein A, Rosenman KD, et al. Increased urinary enzyme excretion in workers exposed to nephrotoxic chemicals. Am J Med 1984;76:989-98.

8 Perry HM, Perry EJ. Normal concentrations of some trace metals in human urine: changes produced by ethylenediaminetetraacetate. J Clin Invest 1959;38:1452-63.

9 Lauwerys RB, Roels HA, Regniers M, et al. Significance of cad- 
mium concentration in blood and urine in workers exposed to cadmium. Environ Res 1979;20:273-9.

10 Falck FY, Fine LJ, Smith RG, et al. Occupational cadmium exposure and renal status. Am J Ind Med 1983;4:541-9.

11 Elinber CG, Edling C, Lindberg E, et al. Assessment of renal function in workers previously exposed to cadmium. $\mathrm{Br} J$ Ind Med 1985;42:754-60.
12 Stonard MD, Chater BV, Duffield DP, et al. An evaluation of renal function in workers occupationally exposed to mercury. vapor. Int Arch Occup Environ Health 1983;52:177-89.

13 Alderman MH, Melcher L, Drayer DE, Reidenberg MM Increased excretion of urinary N-acetyl-B-D-glucosaminidase in essential hypertension and its decline with hypertensive therapy. N Engl J Med 1983;309:1213-7.

\section{Destruction of manuscripts}

From 1 July 1985 articles submitted for publication will not be returned. Authors whose papers are rejected will be advised of the decision and the manuscripts will be kept under security for three months to deal with any inquiries and then destroyed. 